\title{
Thin Bandwidth Knowledge of Results (KR) Improves Performance Consistency on Motor Skill Acquisition
}

\author{
Aline Horta Miguel Junqueira ${ }^{1}$, Rodolfo Novellino Benda ${ }^{2}$, Suziane Peixoto dos Santos ${ }^{3}$, \\ Guilherme Menezes Lage ${ }^{2}$, Márcio Mário Vieira ${ }^{4}$, Maria Flávia Soares Pinto Carvalho ${ }^{4}$, \\ Herbert Ugrinowitsch, ${ }^{4}$
}

${ }^{1}$ Physical Education Department, School of Physical Education, Faculdade Pitágoras, Betim, Brazil

${ }^{2}$ Physical Education Department, Universidade Federal de Minas Gerais, Belo Horizonte, Brazil

${ }^{3}$ Sport Sciences Department, Universidade Federal do Triângulo Mineiro, Uberlândia, Brazil

${ }^{4}$ Sports Department, Universidade Federal de Minas Gerais, Belo Horizonte, Brazil

\section{Email address:}

alinehort@hotmail.com (A. H. M. Junqueira), rodolfobenda@yahoo.com.br (R. N. Benda), suzi.ps@ig.com.br (S. P. Santos), menezeslage@gmail.com (G. M. Lage), totscarvalho@yahoo.com.br (M. F. S. P. Carvalho), marciogin@gmail.com (M. M. Vieira), herbertu@ufmg.br (H. Ugrinowitsch)

\section{To cite this article:}

Aline Horta Miguel Junqueira, Rodolfo Novellino Benda, Suziane Peixoto dos Santos, Guilherme Menezes Lage, Márcio Mário Vieira, Maria Flávia Soares Pinto Carvalho, Herbert Ugrinowitsch. Thin Bandwidth Knowledge of Results (KR) Improves Performance Consistency on Motor Skill Acquisition. American Journal of Sports Science. Vol. 3, No. 6, 2015, pp. 115-119. doi: 10.11648/j.ajss.20150306.13

\begin{abstract}
The bandwidth knowledge of results in one way of supplying feedback during practice, which provides control over the amount and type of information given to the subject. The present study investigated the best distribution of this information throughout the practice. A task requiring to perform a sequence of movements on the keypad, in order to achieve a specific the target time. The experiment consisted of three stages: a) acquisition (50 attempts); b) transfer, ten minutes after the end of the acquisition (10 attempts); c) retention, twenty-four hours after the end of the acquisition (10 attempts). Participants were distributed into four groups: wide bandwidth, with a range of 20\%; narrow bandwidth, with a range of 5\%; increasing bandwidth, with a range of $5 \%$ on the first half of the acquisition and $20 \%$ on the second half; and decreasing bandwidth, with a range of $20 \%$ on the first half and $5 \%$ on the second one. The results show thin bandwidth improves performance consistency.
\end{abstract}

Keywords: Motor Skill, Motor Learning, Bandwidth Feedback

\section{Introduction}

Information about practice is necessary to improve error detection and consequently skill acquisition. This information can be related to motor pattern [1] or even about movement result [2]. Although in the 1950's it was believed that the highest amount of feedback improved skill acquisition [3], Salmoni, Schmidt and Walter [4] showed that small amount of information improved skill acquisition. Bandwidth feedback reduces the amount of quantitative information (i.e., Knowledge of Results - KR) provided to the learner since quantitative information related to performance is provided only when the error overpass the established bandwidth $[5,6]$. In this case, corrections are required to be performed. However, if performance is inside the bandwidth, quantitative feedback is not provided [7], performance is considered correct [8] and corrections are not necessary.
Although another modalities to provide feedback have a higher amount of studies (e.g., frequency) than bandwidth, it is interesting to note that bandwidth feedback seems to improve motor learning [9] because the moment to provide information on frequency or average feedback is determined by the researcher and on bandwidth is determined by the learner performance $[10,11]$. In other words, when one adopts bandwidth feedback, the learner performance determines the moment feedback should be provided [8]. Consequently, quantitative information that conducts planning corrections combination with qualitative information that conducts to stable behavior improved skill acquisition [9].

Many studies compared the effects of thin with wide bandwidth feedback $[7,8,9,11,12,13,14]$. In general the results showed wide bandwidth improves skill acquisition when compared to thin bandwidth. Two hypotheses are mostly adopted to explain these results: maladaptive short-term corrections [15] 
and consistency $[16,17]$. More constant feedback provided by thin bandwidth can conducts to constant corrections, which result on maladaptive short-term corrections. On the other hand, wide bandwidth provides smaller number of quantitative information requiring smaller number of changes on action plan; consequently, performance becomes more consistent.

Since different bandwidth feedback improved skill acquisition, some studies have combined different bandwidths of feedback and it was expected to find different results when compared to only one bandwidth adopted during the whole experiment. Bandwidths of $15 \%$ and $0 \%$ were combined and compared to $15 \%$ plus $0 \%$ [16]. Both groups, $15 \%$ and combined $(15 \%$ plus $0 \%)$ presented more stable pattern than group $0 \%$ showing that bandwidth feedback improves skill acquisition and wide bandwidth should not ben necessary after learning motor pattern. Goodwin and Meeuwsen [9] also have tested combination of bandwidths with four groups: group $0 \%$, group $10 \%$, decreasing bandwidth (started with $20 \%$ and diminished to $15 \%, 10 \%, 5 \%$ and $0 \%$ ), and increasing, with the amplitude of bandwidth increasing exactly in opposite direction to decreasing group. The wide bandwidth feedback at the end of the learning phase deteriorated skill acquisition, probably because the small amount of quantitative feedback (wide bandwidth) at the last part of learning phase diminished the ability of error correction. However, Lai and Shea [17] and Coca-Ugrinowitsch et al [7] found that wide bandwidth improved skill acquisition, probably because small amount of $\mathrm{KR}$ produced by wide bandwidth reduced corrections and increased performance consistency $[16,17,18]$.

Summarizing, Goodwin and Meuwsen, [19] tested the combination of no bandwidth with $20 \%$ of bandwidth of feedback and compared with a different bandwidth (10\%) and no bandwidth at all ( $0 \%$ of bandwidth). This design does not allow understanding whether crescent or decreasing bandwidth are better to motor learning than a thin or wide bandwidth of feedback.

Based on the results presented above, this study investigated the effect of thin, wide, crescent and decreasing bandwidth feedback on both, performance accuracy and consistency. Our hypothesis is that decreasing and thin bandwidth feedback will conduct to better performance consistency than crescent and wide bandwidth feedback.

\section{Method}

\subsection{Sample}

Sixty university volunteers self-declared right-handed, from both sexes, aged from 18 to 35 years old with no experience on the task participated as volunteers on this study. Volunteers signed the consent term preceded the experiment. The protocol was approved by the local ethics committee of the Universidade Federal de Minas Gerais. The study was performed in accordance with the ethical standards established in the 1964 Declaration of Helsinki amended in 1989.

\subsection{Instrument and Task}

The instruments adopted on this study were a computer with specific software for data collection and analysis and a numeric keyboard connected to the computer. The task consisted of pressing the keys 2, 8, 6, 4 aiming to reach and pre-established target time.

\subsection{Experiment Design and Procedures}

The sixty volunteers were randomly distributed on four groups $(n=15)$ accordingly to the bandwidth of KR: thin bandwidth (TG), wide bandwidth (WG), crescent bandwidth (CG) and decrescent bandwidth (DG). The study had one acquisition phase with 50 trials, when volunteers should press the sequence 2,8,6,4 from the numeric keyboard with the time target of $900 \mathrm{~ms}$ and KR was provided accordingly to the group. The KR was provided to TG when Absolute Error (AE) exceeded the bandwidth of $5 \%$ in relation to the time target (AE higher than 22,5 ms); to the WG RK was provided when AE exceeded the bandwidth of $20 \%$ (AE higher than $60 \mathrm{~ms}$ ). The CG received KR when AE exceeded the bandwidth of $5 \%$ on trials 1 to 25 and the bandwidth of $20 \%$ on trials 26 to 50 ; to the DG on inverse condition. Ten minutes later it was conducted the transfer test with the target time of $1300 \mathrm{~ms}$ and 24 hours later it was conducted the retention test in the same condition as the acquisition phase. Both tests were run without KR supply. Before the experiment all volunteers received instructions about the task and the experiment.

\subsection{Data Analyzes}

All data were organized in blocks of five trials, resulting in ten blocks on acquisition phase plus two blocks of transfer test and two more blocks of retention test. The effects of bandwidth KR were analyzed on performance accuracy (Constant Error - CA) and performance consistency (Standard Deviation) by two way ANOVA. We adopted the post hoc of Tukey for pair comparison and $\mathrm{p} \leq .05$.

\section{Results}

\subsection{Acquisition Phase}

Data analyses are presented separated by phase of the study. First of all we shows data from acquisition phase, followed by transfer test and at last data from retention test.

The analysis of Figure 1a from acquisition phase shows that although performance accuracy was similar between groups $\left[\mathrm{F}(3,56)=0.479, \mathrm{p}=.69, \mathrm{n}^{2}=.14\right]$, performance accuracy increased significantly with practice $[\mathrm{F}(9,504)=15.007, \mathrm{p}$ $\left.<.01, \mathrm{n}^{2}=1,00\right]$ and the Tukey test detected that accuracy increased from the first and second blocks to all the other block $(\mathrm{p}=.03)$. Moreover, there was significant interactions $\left[\mathrm{F}(27,504)=5.268, \mathrm{p}=.01, \mathrm{n}^{2}=.99\right]$ and the Tukey test detected that TG was less accurate on the first block $(p=.02)$ but with practice all groups finished learning phase with similar performance accuracy $(\mathrm{p}=.38)$.

Figure $1 \mathrm{~b}$ shows that although performance consistency was similar $\left[\mathrm{F}(3,56)=2.224, \mathrm{p}=.09, \mathrm{n}^{2}=.53\right]$, performance consistency increased significantly with practice $[\mathrm{F}(9,504)=$ $\left.3.866, \mathrm{p}<.01, \mathrm{n}^{2}=.99\right]$ and the Tukey test detected that SD 
diminished from the first to all the other blocks $(\mathrm{p}=.01)$. Moreover, there was significant interactions $[\mathrm{F}(27,504)=$ $\left.1.654, \mathrm{p}=.02, \mathrm{n}^{2}=.98\right]$ and the Tukey test detected that $\mathrm{CG}$ has less consistent than the other three groups on the first block $(p=.05)$ but with practice all groups finished learning phase with similar performance accuracy $(\mathrm{p}=.89)$.
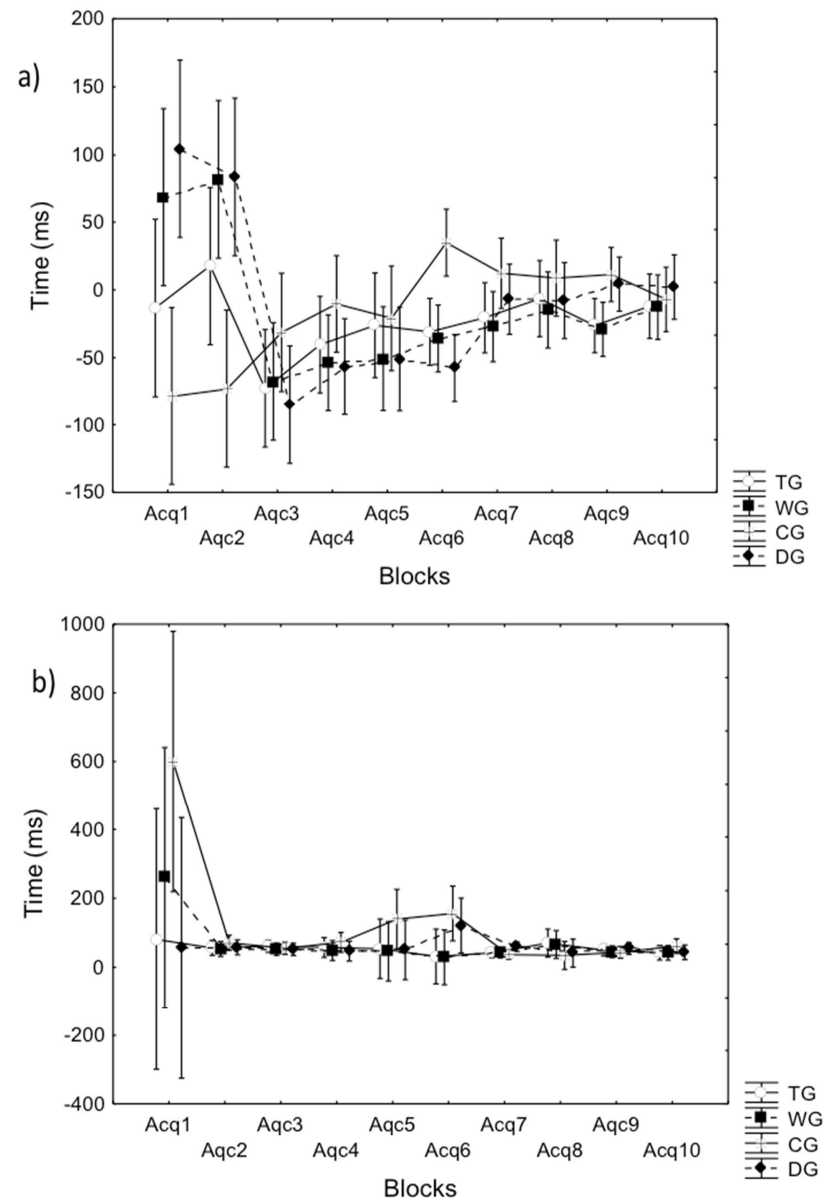

Figure 1. (a) Constant Error (95\% of confidence interval) on the ten blocks of Acquisition phase; (b) Standard Deviation of Constant Error $195 \%$ of confidence interval) on the ten blocks of Acquisition phase.

\subsection{Transfer Test}

Figure $2 \mathrm{a}$ shows that there were no significant interactions between groups and blocks on performance accuracy $[\mathrm{F}(3,56)$ $\left.=2.354, \mathrm{p}<.08, \mathrm{n}^{2}=.56\right]$. Moreover, performance accuracy decreased significantly from the first to the last block of transfer test $\left[\mathrm{F}(1,56)=15.193, \mathrm{p}<.01, \mathrm{n}^{2}=.97\right]$. At last, groups showed significant difference on performance accuracy $\left[\left(\mathrm{F}(3,56)=2.816, \mathrm{p}<.05, \mathrm{n}^{2}=.64\right]\right.$ and the Tukey test detected that TG was more accurate than CG $(\mathrm{p}=.01)$. Figure $2 b$ shows that performance consistency did not change significantly between the two blocks $[\mathrm{F}(1,56)=3.346$, p $\left.<.07, \mathrm{n}^{2}=.43\right]$ and there were no significant interactions [F (3, $\left.56)=0.466, \mathrm{p}<.71, \mathrm{n}^{2}=.14\right]$. However, there was difference on performance accuracy between the four groups $[\mathrm{F}(3,56)=$ $\left.8.248, \mathrm{p}<.01, \mathrm{n}^{2}=.99\right)$ and the Tukey test detected that CG was less consistent that the other three groups $(p=.01)$.
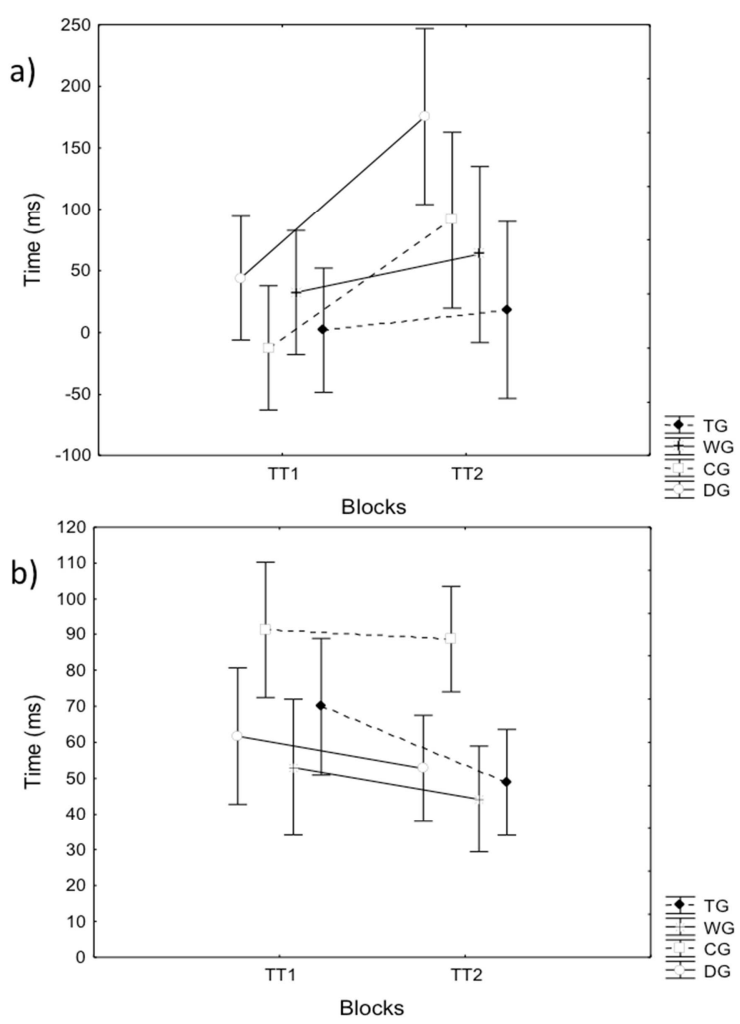

Figure 2. (a) Constant Error (95\% of confidence interval) on the two blocks of Transfer Test; (b) Standard Deviation of Constant Error $195 \%$ of confidence interval) on the two blocks of Transfer Test.
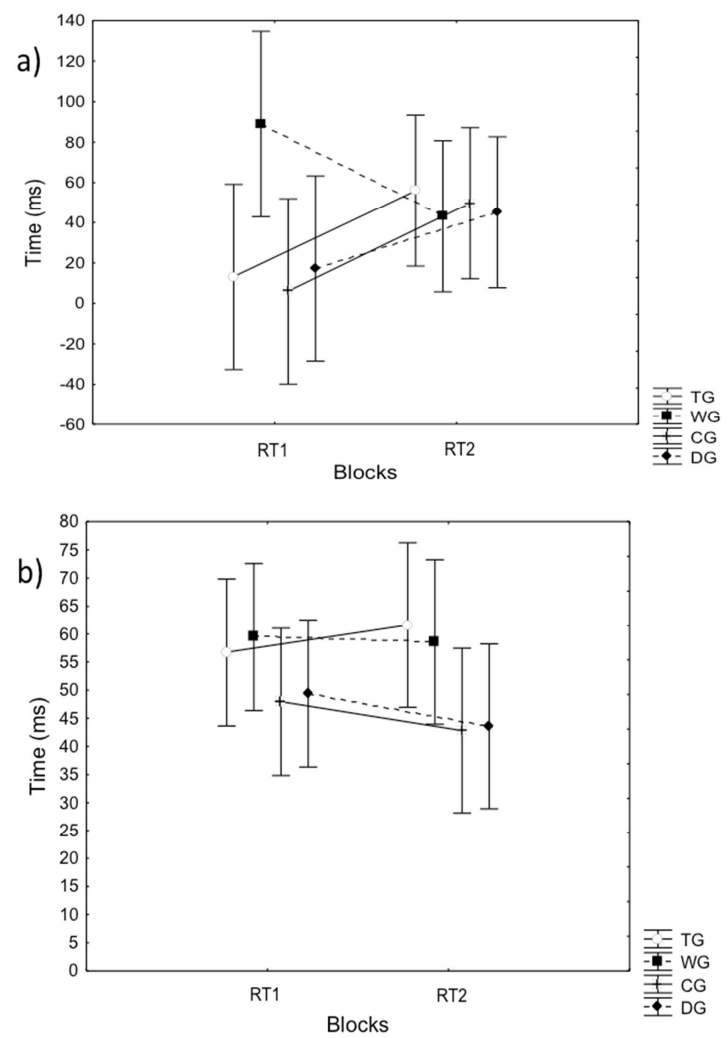

Figure 3. (a) Constant Error (95\% of confidence interval) on the two blocks of Retention Test; (b) Standard Deviation of Constant Error $195 \%$ of confidence interval) on the two blocks of Retention Test. 


\subsection{Retention Test}

Figure 3 a shows that on retention test performance accuracy was similar between the four groups $[\mathrm{F}(3,56)=1.009, \mathrm{p}<.39$, $\left.\mathrm{n}^{2}=.26\right]$ and that performance accuracy did not change significantly between the two blocks $[\mathrm{F}(1,56)=2.249, \mathrm{p}<$. $\left.14, \mathrm{n}^{2}=.31\right]$. However, there were significant interactions $[\mathrm{F}(3$, $\left.56)=3.454, \mathrm{p}<.02, \mathrm{n}^{2}=.74\right]$ and the Tukey test detected that CG was less accurate than the three other groups on the first block $(\mathrm{p}=.01)$. Figure $3 \mathrm{~b}$ shows that performance consistency did not change significantly between the two blocks $(F(1,56)$ $=0.130, \mathrm{p}<.72, \mathrm{n} 2=.06)$ and performance accuracy was similar between the four groups $(\mathrm{F}(3,56)=2.368, \mathrm{p}<.08, \mathrm{n} 2$ $=.56)$. At last, there was no significant interactions $(\mathrm{F}(3,56)$ $=0.256, \mathrm{p}<.85, \mathrm{n} 2=.09)$.

\section{Discussion}

This study aimed to investigate the effect of thin, wide, increasing and decreasing bandwidth feedback on both, performance accuracy and consistency and we tested the hypothesis that increasing bandwidth feedback would decrease performance consistency. The results confirm partially our hypothesis.

First of all, the amount of practice combined with the independent variable allowed the four groups to reach similar performance accuracy and consistency during learning phase. Consequently, any difference observed on transfer or retention tests are considered effects from specific bandwidth feedback [7]. Although wide bandwidth feedback during acquisition phase could result on poor reference for error corrections, and consequently worst performance than the other groups, it did not result on worst performance on both tests. In other words, the small amount of quantitative information combined with qualitative information when performance was inside bandwidth indicates that bandwidth feedback has different effects than frequency of feedback [20]. Probably because quantitative information is related to poor performance and qualitative information is related to good performance.

The analysis of transfer and retention tests shows that crescent bandwidth of feedback is worst to performance than thin, wide and decreasing bandwidth. Accordingly to Goodwin e Meeuwsen [19], high amount of feedback for movement corrections at the end of acquisition phase is as detrimental as high amount during the whole phase. Following this position, crescent bandwidth should deteriorate skill acquisition and we observed this on both tests, but wide bandwidth did not. Probably the high amount of quantitative feedback at the beginning of practice

On the other hand, Lai and Shea [17] found that $0 \%$ of bandwidth at the end of acquisition phase improve skill acquisition. Our results also show that thin bandwidth improved performance accuracy on transfer test.

The results from the present study show that increasing bandwidth half way of acquisition phase deteriorates performance. We have two possible explanations. First, the thin bandwidth adopted at the beginning of acquisition phase was not enough to create a reference for corrections and the combination with wide bandwidth at the last part of acquisition phase makes volunteers lost completely the reference for error corrections. Second, the thin bandwidth at the first part of acquisition phase conducted to mal-adaptive corrections [15] and the wide bandwidth did not provide a reference for error corrections.

The hypothesis was that decreasing and thin bandwidth should increase performance consistency. During transfer test thin bandwidth was more accurate than crescent bandwidth. This difference shows that in the second part of learning phase the wide bandwidth does not provide reference for error correction and deteriorates performance. On the other side, we expected higher consistency of decreasing bandwidth. In fact crescent bandwidth presented lower consistency on transfer test and lower accuracy on retention test in comparison to the other bandwidths. In part this results confirm those found by Ugrinowitsch et al [11] when showed that thin bandwidth improved consistency on tests. Probably participants had enough practice for learning the task and, at this moment, thin bandwidth does not requires constant changes on action plan. Moreover, wide bandwidth at the beginning of practice does not provide reference for error correction [1,7], since wide and decreasing bandwidth have not present higher performance neither on accuracy nor on consistency.

In conclusion, the results of the present study indicate that crescent bandwidth feedback deteriorates both, performance accuracy and consistency. Moreover, thin bandwidth improves performance consistency.

\section{References}

[1] H. Ugrinowitsch, Fonseca, F. S., Carvalho, M. F. S. P., Profeta, V., \& Benda, R. N. Efeitos de faixas de amplitude de CP na aprendizagem do saque tipo tênis do voleibol. [(Effects of the bandwidth KP on the learning of the volleyball tennis serve]. Motriz: Rev. Edu. Fís. vol. 17, pp. 82-92, 2011.

[2] M. M. Vieira, H. Ugrinowitsch, L. Gallo, M. F. S. P. Carvalho, M. Fonseca, M., R. N. Benda. Effects of summary knowledge of results in motor skills acquisition. Rev. Psic. del Dep. vol. 23, pp. 9-14, 2014.

[3] E.A. Bilodeau, I. M. Bilodeau, Variable frequency of knowledge of results and the learning of a simple skill. J. Exp. Psych. vol. 55, p.p. 379-383, 1958.

[4] A. W. Salmoni, R. A. Schmidt, C. B. Walter. Knowledge of results and motor learning: a review and critical reappraisal. Psych. Bul. vol. 95, pp. 355-86, 1984.

[5] D. E. Sherwood, Effect of bandwidth knowledge of results on movement consistency. Perc. Motor Skills, v.66, p.535-542, 1988.

[6] H. Ugrinowitsch, A. A. Coca, I. W. Tertuliano, R. Gimenez, F.A.S. Pereira. Freqüência de feedback como um fator de incerteza no processo adaptativo em aprendizagem motora. [Frequency of feedback as an uncertainty factor on adaptive process in motor learning]. Revista Brasileira de Ciência e Movimento [Bras. J. Scie. Mov.], vol. 11, pp. 41-47, 2003. 
[7] A. A. Coca-Ugrinowitsch, R. N. Benda, L. M. Aburachid, A. G. P. Andrade, P. J. Greco, H. J. K. Menzel, H. Ugrinowitsch. Bandwidth knowledge of results on the learning of the saloon dart throwing task. Perc. Motor Skills, vol. 118, pp. 462-474, 2014.

[8] M. S. Butler, T. G. Reeve, M. G. Fischman. Effects of the Instructional set in the bandwidth feedback paradigm on motor skill acquisition. Res. Quar Exer. Sport, v. 67, p. 355-359, 1996.

[9] A. Badets, Y. Blandin, Observational Learning: Effects of Bandwidth Knowledge of Results. J. Motor Behav. vol. 37, pp.211-216, 2005.

[10] J. E. Goodwin, H. J. Meeuwsen, Using bandwidth knowledge of results to alter relative frequencies during motor skill acquisition. Res. Quart. Exerc. Sport, vol.66, pp.99-104, 1995.

[11] H. Ugrinowitsch, A. A. Coca Ugrinowitsch, I. W. Tertuliano, R. N. Benda, Effect of bandwidth knowledge of results on the learning of a grip force control task. Perc. Motor Skills, vol. 111, p. $643-652,2010$

[12] T. D. Lee, B. K. V. Maraj, Effects of bandwidth goals and bandwidth knowledge of results on motor learning. Res. Quar. Exer. Sport, vol.65, pp.244-249, 1994.

[13] J. H. Cauraugh, D. CHEN, S. J. Radlo, Effects of traditional and reversed bandwidth of results on motor learning. Res. Quar. Exerc. Sport, v.64, p.413-417, 1993.
[14] A. A. Coca Ugrinowitsch, H. Ugrinowitsch, Bandwidth feedback in the learning of a hold task. The FIEP Bulletin, v.74, p.34-37, 2004.

[15] R. A. Schmidt, Frequent augmented feedback can degrade learning: evidence and interpretation. In: J. Requin and G.E. Stelmach (Eds.) Tutorials in Motor Behavior, Kluwer Academic Publishers, 1991, pp. 59-75.

[16] C. J. Winstein, R. A. Schmidt, Reduced frequency of knowledge of results enhances motor skill learning. J. Exp. Psych.: Learning, Memory and Cognition, vol. 16, pp. 677-691, 1990

[17] Q. Lai, C. H. Shea, The role of reduced frequency of knowledge of results during constant practice. Res. Quar. Exerc. Sport, v.70, p.33-40, 1999.

[18] T. D. Lee, H. Carnahan, Bandwidth knowledge of results and motor learning: More than just a relative frequency effect. Quar. J. Exp. Psych., vol. 42, pp. 777-789, 1990.

[19] J. E. Goodwin, H. J Meeuwsen, Using bandwidth knowledge of results to alter relative frequencies during motor skill acquisition. Res. Quart. Exerc. Sport, v. 66, pp.99-104, 1995.

[20] J. Graydon, L. Paine, C. Ellis, R. Threadgold, Comparison of bandwidth knowledge of results and the relative frequency effect in learning a discrete motor skill. J. Human Mov. Stud. vol.32, pp.15-28, 1997. 